\title{
Wind Channeling by the Dead-Sea Wadis
}

\author{
H. Shafir ${ }^{1}$, F. J. Jin ${ }^{1}$, Y. Lati ${ }^{2}$, M. Cohen ${ }^{2}$ and P. Alpert ${ }^{*}, 1$ \\ ${ }^{1}$ Department of Geophysics and Planetary Sciences, Tel-Aviv University, Tel-Aviv, 69978, Israel \\ ${ }^{2}$ Research Unit, Dead-Sea Works, Sdom, Israel
}

\begin{abstract}
Wind channeling by small wadis of few kilometers width at the Dead-Sea area is demonstrated with highresolution modeling. Previous works have not shown such channeling in very small rivers due to computation difficulties on the meso- $\gamma$ and the lack of suitable observations for verification. The wind channeling is demonstrated in three wadis, and was verified by meteorological model simulations on the meso- $\gamma$ scale, as well as by surface and upper layers observations. There are two dominant mechanisms for the wind channeling, the geometrical forcing and the thermal katabatic effect as shown by the model negative divergence zone inside the wadis. The unique features of the Dead-Sea i.e., the absence of vegetation cover and urban areas can serve as a proposed natural model for the wind-wadi interaction.
\end{abstract}

\section{INTRODUCTION}

The first studies of the airmass exchanges between even small valleys and the winds aloft were made by $[1,2]$. The four main mechanisms that can produce distinct relationships between winds above and within a valley were reviewed by [3] with the following mechanisms.

Thermally Driven Process: This process results from the thermal differences in the air density at various points of the valley. During daytime up valley winds exist, and at night down the valley. These winds are pronounced in areas with large diurnal cycles in surface sensible heat fluxes and when upper-level winds are weak.

Forced Channeling: Winds above the valley are channeled by the sidewalls of the valley. Thus, the valley axis determines the direction of the wind flow.

Downward Momentum Transport: Strong downward transport of horizontal momentum from above would produce wind directions within the valley that are similar to the upper winds aloft. This downward transport could be caused by vertical turbulent mixing or by gravity waves. This process most likely occurs during unstable or neutrally stratified conditions in wide flat-bottomed valleys with low sidewalls.

Pressure driven channeling: The winds in the valley are driven by the component of the geostophic pressure gradients along the valley's length. When the air aloft enters the valley, it decelerates and the imbalance of the upper wind forces a leftward deflection in the wind direction. An interesting result of this flow is that wind inside the valley can blow in an opposite direction to the upper-level wind (countercurrent).

\footnotetext{
*Address correspondence to this author at the Department of Geophysics and Planetary Sciences, Tel Aviv University, Tel Aviv, 69978, Israel; Tel: 972-3-6405689; Fax: 972-3-6405205; E-mail: pinhas@cyclone.tau.ac.il
}

Thus, the wind regime inside valleys was attributed by several researchers to one of these mechanisms. For instance [4-6], attributed the flows in shallow rivers to the thermally driven process while [7] in the Rhine Valley, and [8] in the Tennessee Valley attributed the flow in these valleys to the pressure driven channeling mechanism. Other researchers like [9] in the Riviera Valley of Southern Switzerland [10], in other Switzerland valleys [3], in the Tennessee Valley or [11] in the Rio Negro and Limay rivers attributed the wind regimes in these valleys to a mixture of two or more of these causes.

All of these aforementioned studies investigated the wind flows in broad and long valleys and rivers. Only a few studies exist about the wind flow in small rivers of a few kilometers e.g. [12-13]. We are not aware of studies which investigated the wind-flow in small wadis using meteorological mesoscale model along with observations except for one. Only recently [14] used the WRF model to simulate meandering flows over quasilinear ridge-valley topography using finest nest resolution of $444 \mathrm{~m}$. The reason for this lack of studies is that not only the meteorological mesoscale models on the meso- $\gamma$ scale (order of $1 \mathrm{~km}$ ) are still relatively rare, but also the lack of suitable measurements in such small areas.

Here, the wind flows in very small three rivers (wadis) of a few kilometers width in the Dead-Sea area and below mean-sea-level are investigated. We run a meteorological meso-scale model (MM5) as well as special observation periods in the Dead-Sea area in which we are observing the Dead-Sea climate by several surface stations and by radiosondes. The wind channeling by these small wadis is demonstrated by meso- $\gamma$ model runs, some surface observations and vertical profiles measurements.

Section 2 describes the study area and the observational details. Section 3 summarizes the model results and Section 4 the surface and upper-layers observation results. Section 5 summarizes the results and the conclusions. 


\section{STUDY AREA AND OBSERVATIONS DETAILS}

The study area is located in the Dead-Sea valley in southern Israel (Fig. 1). We focused on two wadis the Chemar and the Zeelim. Both wadis are very similar in their structure. Both fall from about $600 \mathrm{~m}$ to $-400 \mathrm{~m}$, and their highest depths (near their estuaries) are about $300 \mathrm{~m}$. The length of the Chemar Wadi is about $25 \mathrm{~km}$ and the Zeelim length is about $16 \mathrm{~km}$. We performed a special observational period (SOP) of two days in Summer (5/9-7/9/2005) in which we observed the atmospheric fields in several ground stations as well as by radiosondes. Two of these stations are located against the estuaries of the two wadis as follows. P8 is at Zeelim Wadi estuary while Nve-Zohar is at Chemar Wadi estuary (Fig. 1). A third wadi on the east side of the Dead-Sea - Ash Shaqayq Wadi was also investigated; however, we are in lack of information for this wadi. P8 is a ground station which measured wind speed and direction, temperature and relative humidity in every 10 minutes during the SOP. In Nve Zohar we measured the vertical profiles by radiosondes and observed the ground data during the

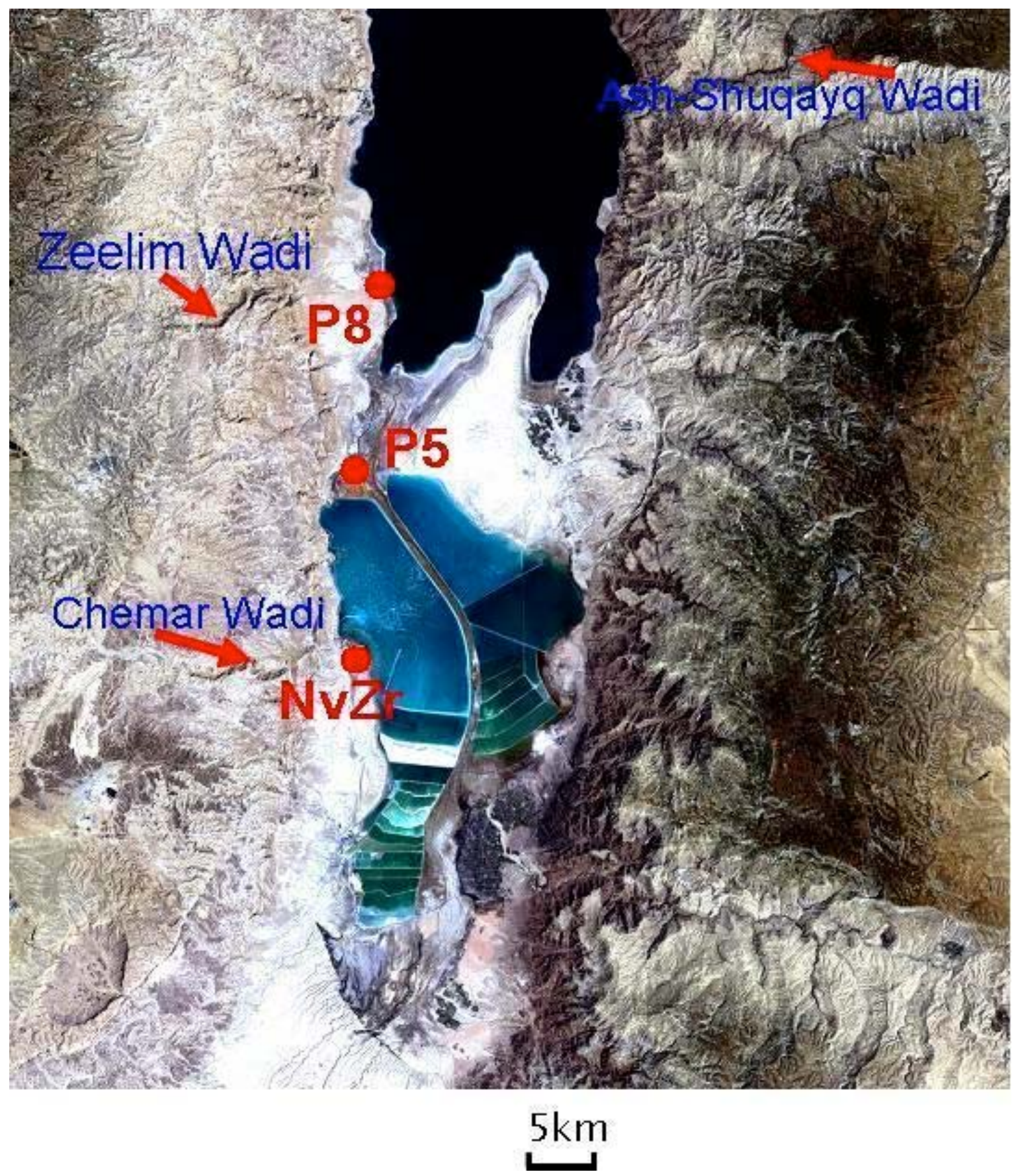

Fig. (1). The south Dead-Sea satellite picture of observational stations (in red) and wadis (in blue) used in this study. The satellite picture was taken from the United Nations Environmental Program (UNEP) DEWA/GRID-Europe webpage (http://www.grid.unep.ch/activities/ global_change/atlas/atlas_examples.php). The picture was taken in the year of 2001. In the southern part evaporation ponds of the Dead-Sea Works are noticed. 
SOP. The P5 station (Fig. 1) was employed as a control station in contrast to $\mathrm{P} 8$, because both stations are very close, but there is no wadi near P5. P5 is also a ground station which measured every 10 minutes.

The climate of the Dead-Sea is very hot and dry. It is in an arid zone having large differences in the diurnal temperature cycles. The breeze of the Dead-Sea slightly tempers the hot and dry climate [15]. The two dominant features in the daily oscillation of the wind are the local Dead Sea breeze and the Mediterranean breeze. As shown by [16] the DeadSea valley winds are dominated by a relatively high mesoscale index of activity particularly in summer. The Dead-Sea breeze blows during the morning to noon hours with moderate speeds of up to $5-6 \mathrm{~m} / \mathrm{sec}$ and north-easterly direction in the southern Dead-Sea. The Mediterranean breeze originates at the Mediterranean coast and is pronounced mainly in spring and summer [17]. During the day it flows up the Judean hills, and it drops into the Dead-Sea valley in the early evening hours. Hence, this flow descends about $1200 \mathrm{~m}$ from the Judean Mountains to the Dead-Sea at about $-420 \mathrm{~m}$ below MSL. This fall speeds up the wind, and the adiabatic heating warms and dries the Dead-Sea area. This wind can reach a peak speed of over $15 \mathrm{~m} / \mathrm{sec}$ for short periods and has a north-westerly direction at the southern part of the DeadSea. During night and early morning hours the nocturnal winds prevail in the Dead Sea Valley.

\section{WIND CHANNELING BY WADIS VERIFIED BY MODEL SIMULATIONS}

\section{a. Model Description}

The model used in this study is the MM5 (Mesoscale Model Version 5) which was developed at the National Center for Atmospheric Research (NCAR) and Penn State University [18]. The main features of the MM5 model are (i) a multiple-nesting capability, (ii) nonhydrostatic dynamics which allows the model to be used down to a few-kilometer grid scale, (iii) multitasking capability on shared- and distributed-memory machines, (iv) a four-dimensional dataassimilation capability, and (v) more physics options. A detailed description of the MM5 modeling system can be found at [18]. This model is run operationally at Tel Aviv University. It solves the full flow equations in the meso-scale and uses the terrain following sigma-coordinates. The initialized data to drive the model was from the GFS (global forecast system) network. The model system is convenient for changes; therefore, we were able to make the required changes by setting up the appropriate relevant parameterizations to accurately reflect the unique characteristics for the simulations in the special area of the Dead-Sea. This area has steep changes in the topography, and negative terrain values with respect to sea-level height. These topographic negative values were considered in the land-use file. It has been found that the Mediterranean Sea has a remote influence on the local climate of Dead Sea region, especially with regard to the temperature, humidity and wind fields. Therefore, the nearby sea was taken into consideration during the designing stage of our model. Three nested grids were employed. Their domain sizes from the coarse to fine were 864,477 square km (62x55 grid points), 144,866 square $\mathrm{km} \mathrm{(73 \times 70} \mathrm{grid}$ points) and 18079 square $\mathrm{km}(94 \times 61$ grid points). The resolutions of the three grids from coarse to fine are: 16.2, 5.4 and $1.8 \mathrm{~km}$ respectively (Fig. 2). The locations of the grid centers from the coarse grid to fine were $31.5 \mathrm{~N} 34.5 \mathrm{E}$, $31.45 \mathrm{~N} 35.15 \mathrm{E}$ and $31.4 \mathrm{~N} 35.48 \mathrm{E}$ respectively. The interaction between the grids was only in one way direction from the coarse grid to the fine. In every grid there are 43 vertical levels (19 levels in the lowest $1 \mathrm{~km}$ ), and the simulation was carried out for the Special Observation Period (SOP) for 48 hours from 5/9/05 00UTC to 7/9/05 00UTC. The total grid points inside each wadi are determined by the principle of how to select the size of wadi, due to our relative high horizontal resolution, the size of wadi even selected conservatively, for instance, $\mathrm{NvZr}$ is about $4 \mathrm{~km}$ times $12 \mathrm{~km}$, and P8 is about $4 \mathrm{~km}$ times $10 \mathrm{~km}$, there are at least 10 and 8 grid points inside each wadi respectively, therefore, the finest resolution of $1.8 \mathrm{~km}$ can catch the accurate wind-flow patterns.

\section{b. Validation of the Model}

In this section we are discussing the verification of the MM5 model. Fig. (3) shows the agreement between the model wind vertical profile and the radiosonde observation in Nve-Zohar. Fig. (4a-c) show the agreement between the model and the observations of wind, temperature and specific humidity respectively in the ground station of P8. Fig. (5a-c) show the same agreement in P5.

In general, it seems that the model performs quite well. The model shows the temperature and humidity maxima and minima in their right times. It seems that the model underestimate the temperature in P8 and P5 and overestimate the humidity. This can be the outcome of the reason that the model does not take into consideration the Dead-Sea drying that has occurred recently. The Dead-Sea drying caused a shrink of the Dead-Sea area, increase of the Dead-Sea salinity and of the SST, a weakening of the Dead-Sea breeze and a decrease in the humidity in the Dead-Sea neighboring areas [15]. All of these might be the reason that the model temperature was underestimated in Figs. $(\mathbf{4 b}, \mathbf{5 b})$, and the humidity was overestimated in Figs. (4c,5c). Another possible reason for this disagreement between the model and observations of the absolute values of the temperature is that the models parameters as shown in Figs. $(\mathbf{4 b}, \mathbf{5 b})$ were measured at the first sigma level which is at about $10 \mathrm{~m}$ above the ground while the observations were taken on ground levels of $1-2 \mathrm{~m}$. This higher model measurement tends to reduce the temperature in the model with respect to the observations.

It should be noted, however, that these model limitations do not affect the wind-western flows effect and the wadis channeling shown in the next sections.

\section{c. Wind Channeling by the Wadis Simulated by the Mesoscale Model}

Fig. (6) shows the simulated wind field pattern at 3:00 a.m. UTC of 6 th Sep 2005. The reason for this chosen time is that the wind due to the synoptic system has a minimum influence on our interested research region due to high 


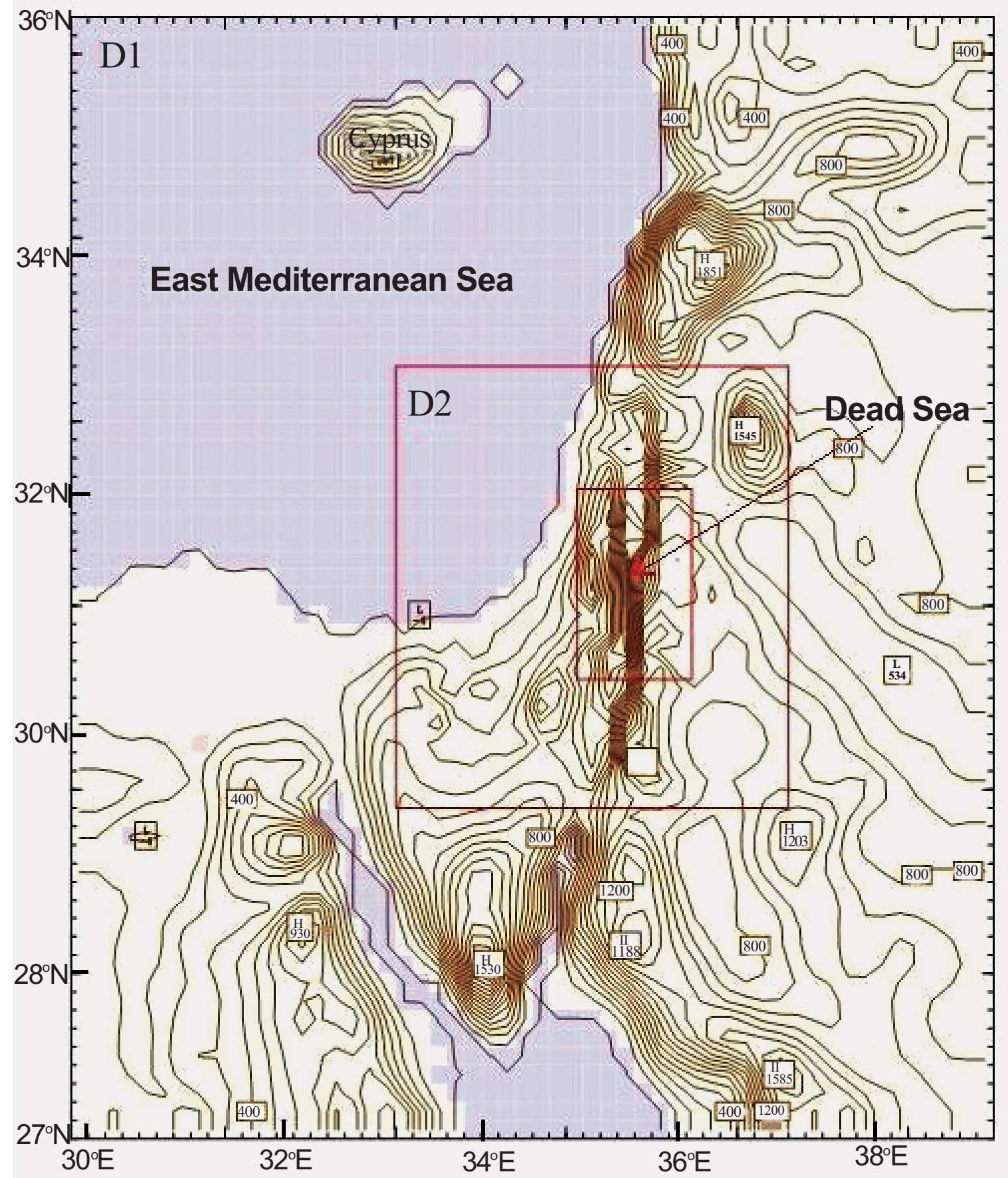

Fig. (2). The location of the three model domains. The horizontal grid intervals of the domains from fine to coarse are: $1.8 \mathrm{~km}, 5.4 \mathrm{~km}$ and $16.2 \mathrm{~km}$ respectively.

stability near the surface. Therefore, the wind pattern is primarily the result of local near-surface forcing. By simply considering the whole Dead Sea area as a valley of meso- $\beta$ scale $(20-200 \mathrm{~km})$, the flow pattern of the wind clearly shows that the thermally driven process dominates the wind regime, the temperature gradient between the land and sea results in the air flows down to the Dead Sea valley from surrounding region. However, a careful check for the three meso- $\gamma$ wadis inside the Dead Sea regions shows that except to the above mentioned mechanism, the forcing due to the channeling can be identified clearly near the axis of the three wadis, i.e. the wind flows down to Dead Sea valley along the axis of respective wadis, especially, an extremely strong forcing channeling flow can be seen at Ash Shaqayq Wadi to the east side of the Dead Sea (Fig. 6).

To further investigate the mechanism which influences the wind regime in the wadi regions, the zoomed compound charts for the Zeelim wadi and the Chemar Wadi are shown in Fig. (7a,b), respectively. Fig. (7a) shows that a manifest strip of negative wind divergence, i.e., wind convergence 


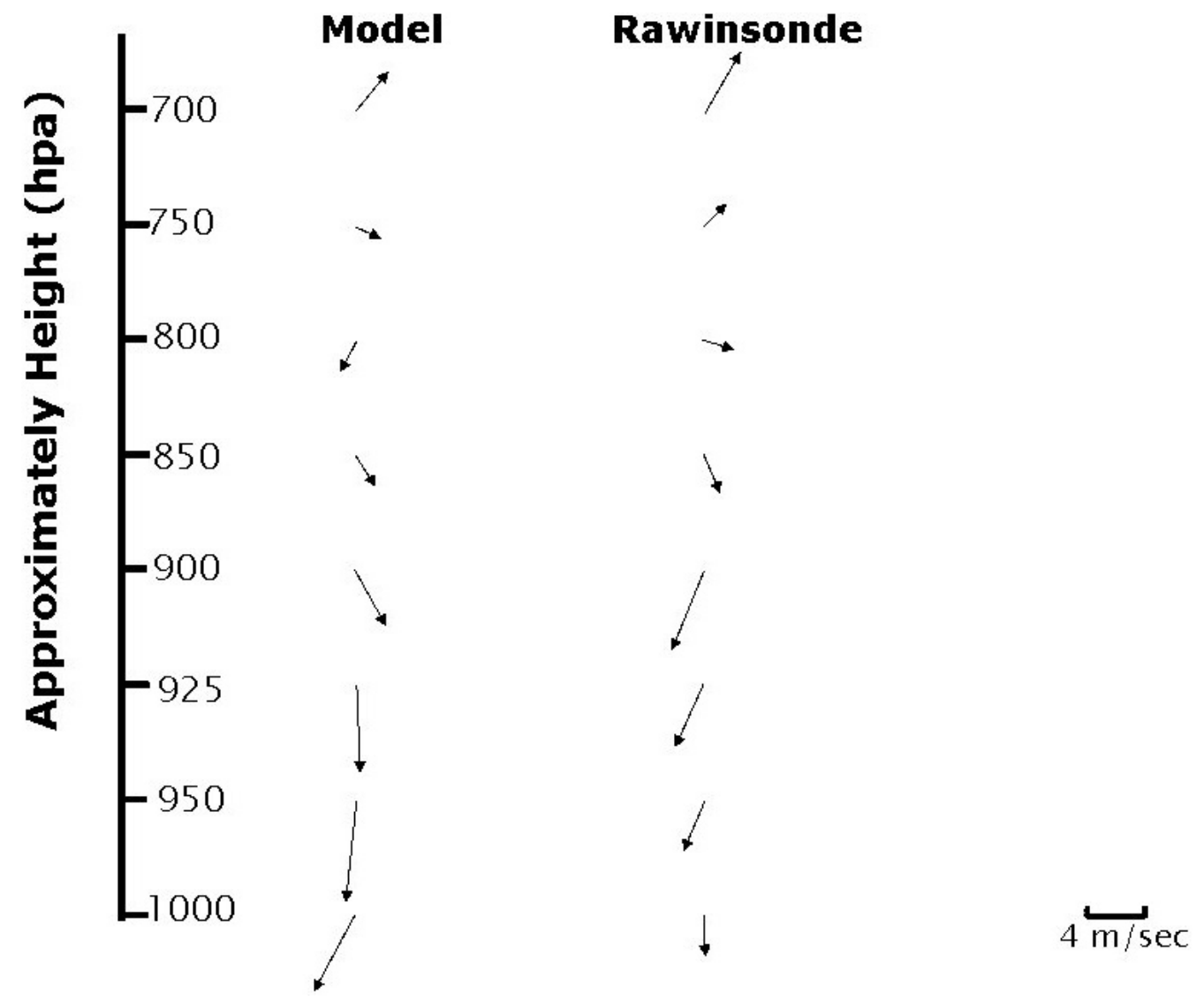

Fig. (3). Comparison of wind speed and direction for 6th Sep. 2005 at 3:00 a.m. local time (Nvzr).

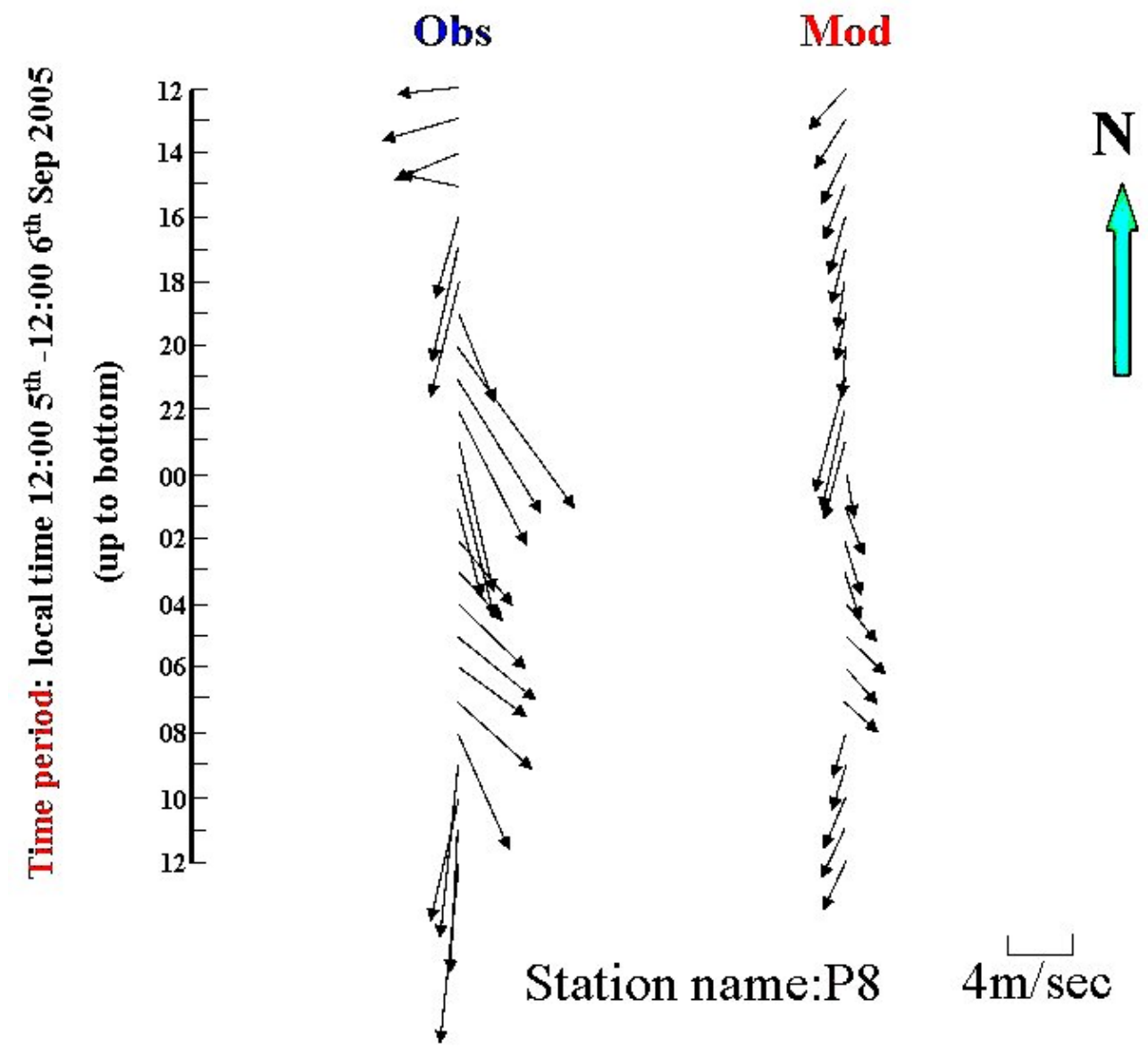

Fig. (4a). Model against ground-level observations of the wind vectors during the SOP in P8. 
Model against observations of the temperature in P-8 during the SOP

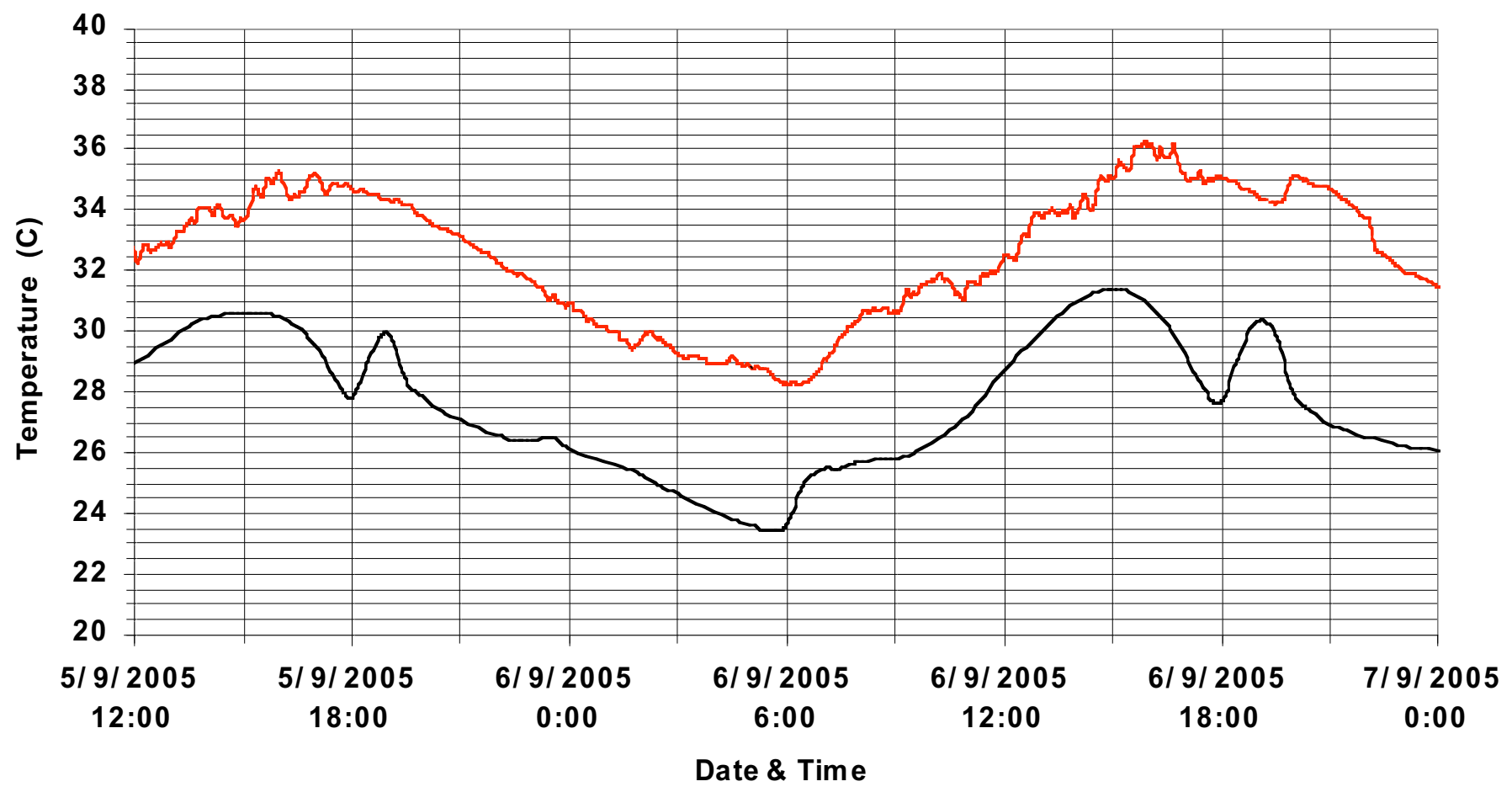

- P-8 model - P-8 obs

Fig. (4b). Model against observations of the temperature in P-8 during the SOP.

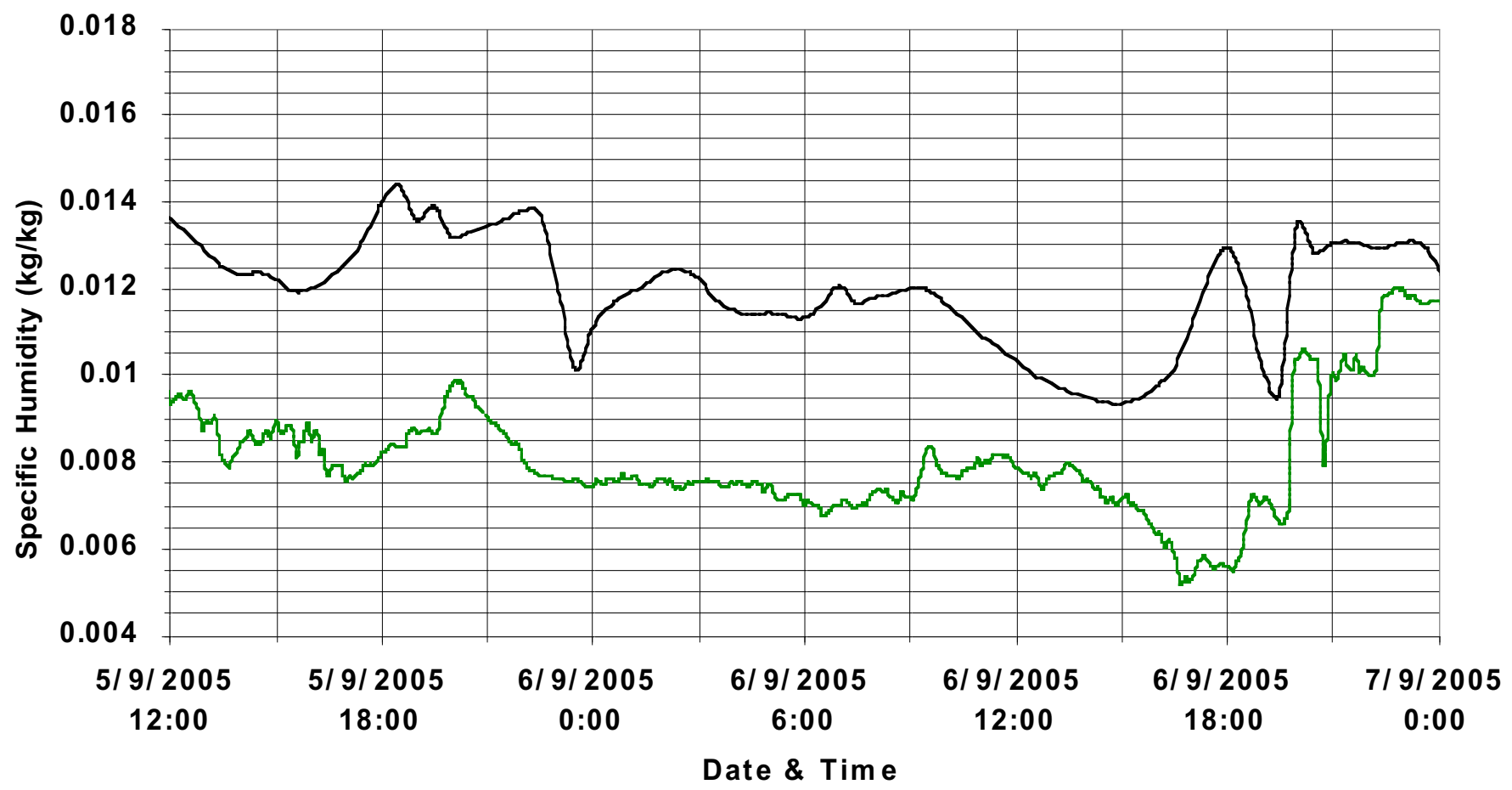

- P-8 model -P-8 obs

Fig. (4c). Model against observations of the specific humidity in P-8 during the SOP. 


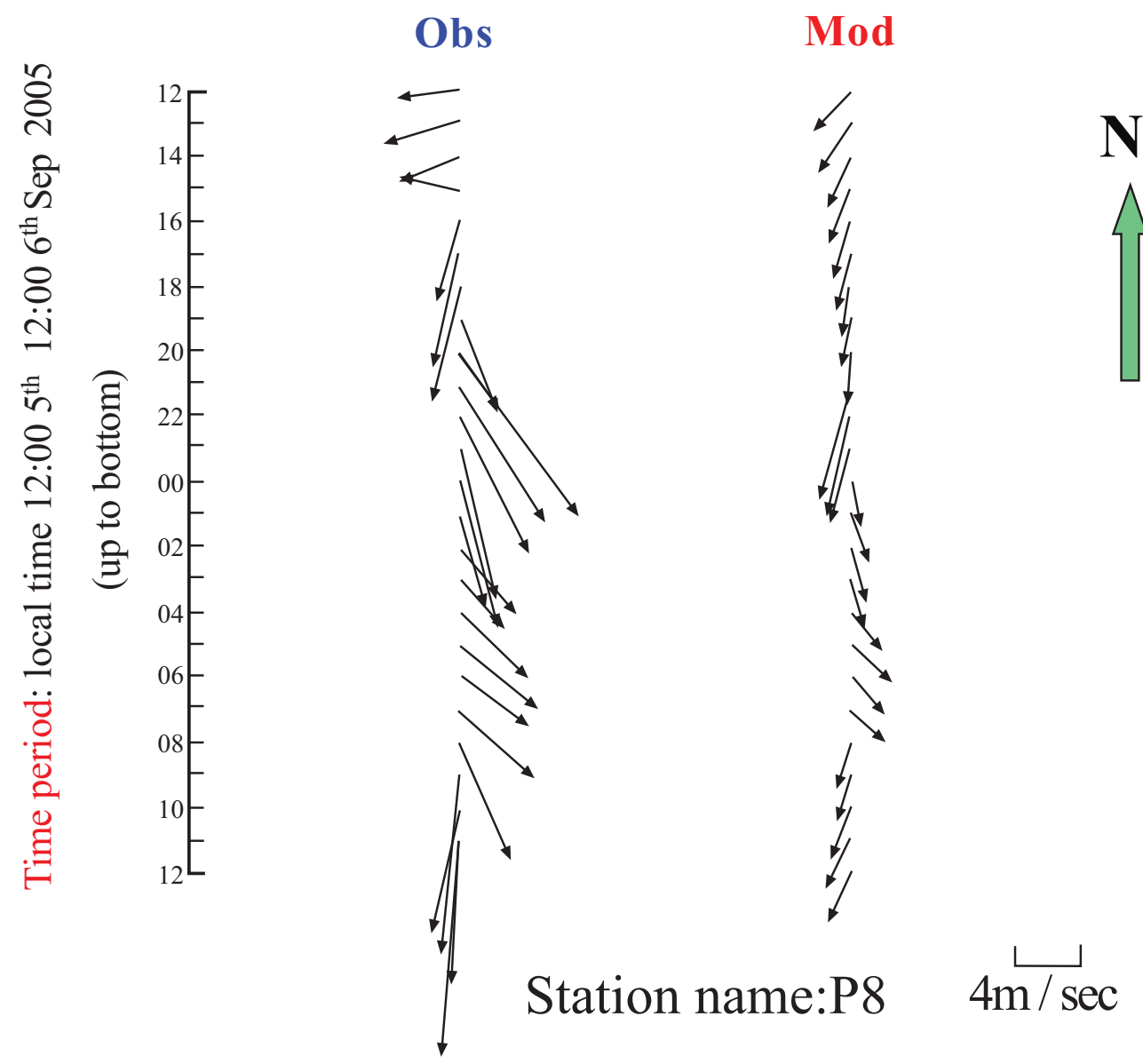

Fig. (5a). Comparison of surface wind fields between observed and model output data - P5.

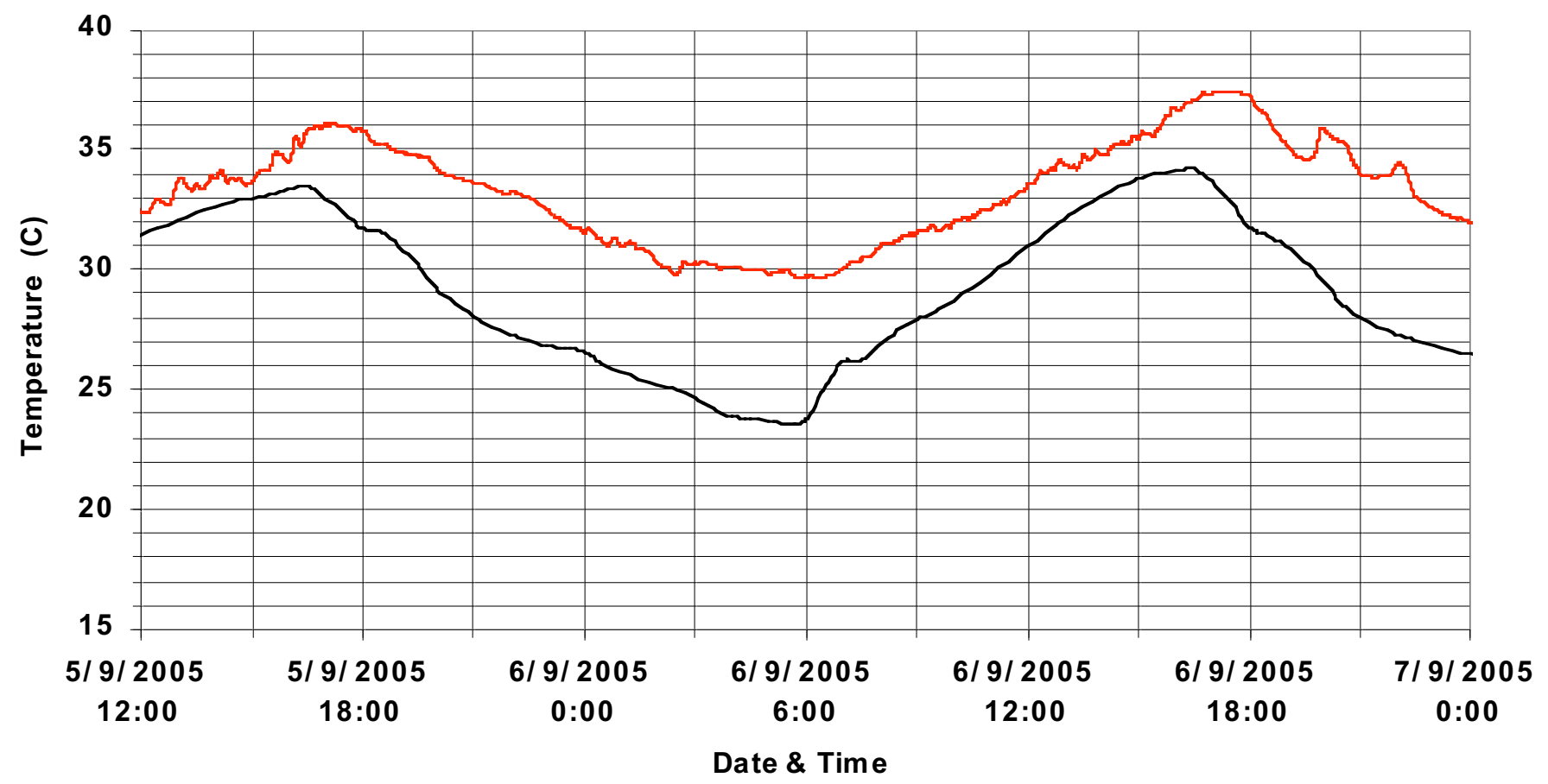

\section{P-5 model - P-5 observation}

Fig. (5b). Model against observations of the temperature in P-5 during the SOP. 


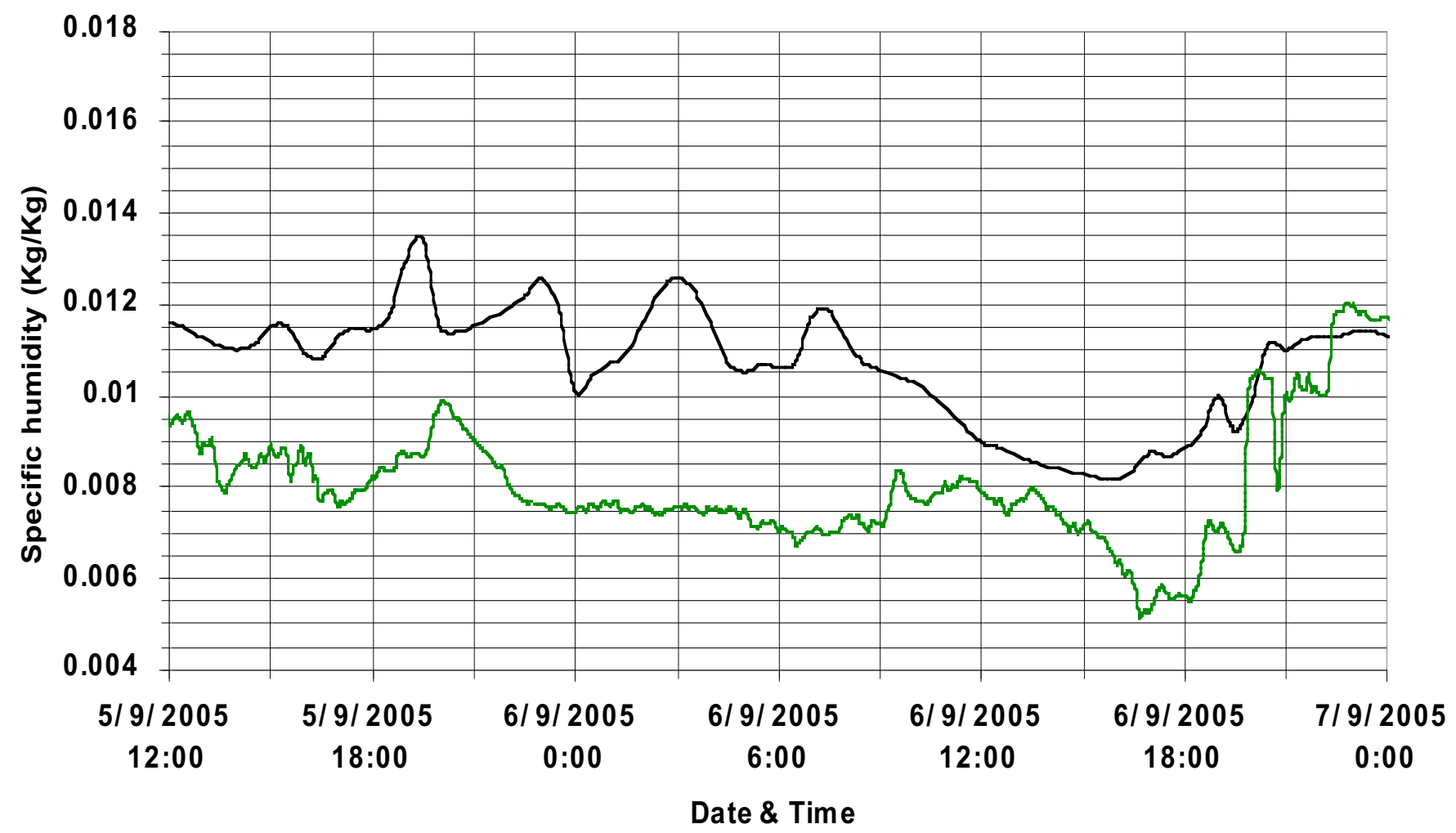

\section{-P.5 model - P-5 observation}

Fig. (5c). Model against observations of the specific humidity in P-5 during the SOP.

zone, is located close to the axis of the Zeelim Wadi, and two secondary-peaks of negative wind divergence with the central values of $-0.0007 \mathrm{~s}^{-1}$ and $-0.0009 \mathrm{~s}^{-1}$ are located at the most western and most eastern part of Zeelim Wadi. It is interesting to note that the nearly no friction of the Dead-Sea water makes the wind magnitude to be maximized after crossing the Dead-Sea shoreline. Dynamical reasons can well explain the reason of existing negative wind divergence zone along the wadi. It is either due to the deceleration of horizontal wind flow or a convergent motion of air mass toward the center of wadi. Furthermore, these two mechanisms are exactly the result of local dominant factors during the process of wind blowing. The wall of the wadi can be a blocking factor to the normal flow of the wind, causing wind convergence, and the thermally driving mechanism may have a more important role for the formation of the negative wind divergence zone along the wadi. Since, during the night time or the early morning the down valley wind flow pattern result in a strong convergence in the center of wadi. Fig. (7b) shows similar features like Fig. (7a), but a more clear peak of negative wind divergence located at the center of Chemar Wadi with a maximum value of $-0.0004 \mathrm{~s}^{-1}$. The finding of a negative wind divergence zone inside the two wadis support the existence of the two main dominant factors that influence the wadi wind regime in our research region, i.e. thermally driving and also the channeling forcing mechanism shown in Fig. (6).

\section{WIND CHANNELING BY WADIES VERIFIED BY OBSERVATIONS}

\section{A. Vertical Profiles}

Tables 1A and 1B show the measured wind profiles up to $1 \mathrm{~km}$ for 5 Sep. 2005 21:00 LT and 7 Sep. 2005 06:00 LT respectively. The measurements were made at the Nve-Zohar station (Fig. 1) and included ground observations. In order to verify the channeling we compare the ground wind to the wind aloft. From these tables it has become clear that at night there are considerable differences between the ground and the $0-150 \mathrm{~m}$ above ground observations, and the wind aloft. For instance, on 5/9/05 at 21:00 the ground and 0$150 \mathrm{~m}$ observation both show wind direction of $330^{\circ}$, while at the upper layers the wind direction changes to North-NorthEasterly. Similarly, on 7/9/05 at 06:00 ground wind direction is $230^{\circ}$ and at $0-150 \mathrm{~m}$ altitude it is $316^{\circ}$, while the upper layers show again North-North-Easterly directions. These results suggest that the Chemar Wadi which is located next to Nve-Zohar is channeling the winds from North direction to its axis of Westerly direction. There is a small tilt in the wind direction from westerly wind as determined by the wadi toward the north, and as determined by the upper-level wind 


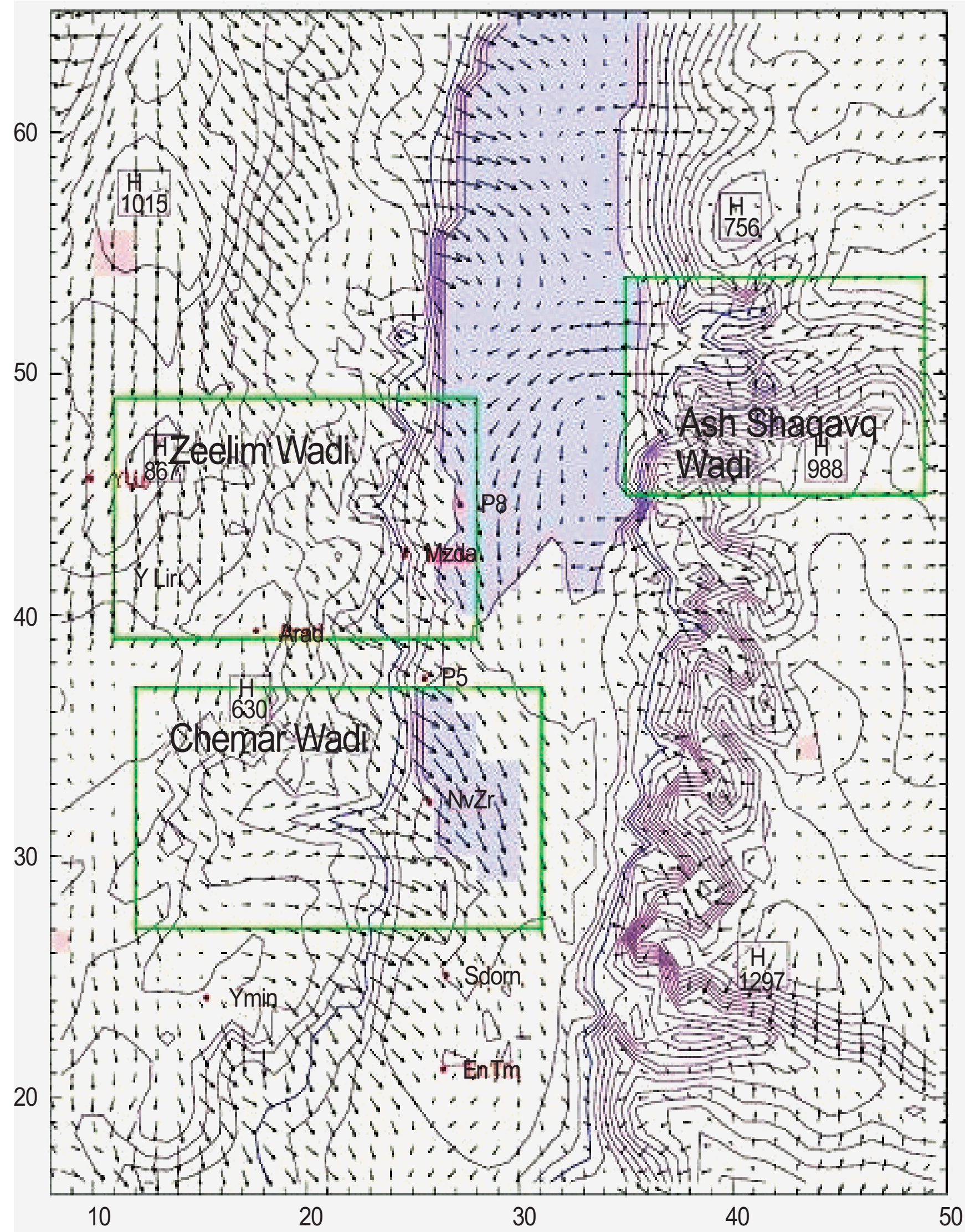

Fig. (6). Wind flow vectors, three wadis and contour line of topography at 3:00 UTC $6^{\text {th }}$ Sep 2005 . The interval of contour line is 100 meters. Blue line indicates the zero Dead sea level height, which is $-420 \mathrm{~m}$ relative to Mediterranean sea level. 


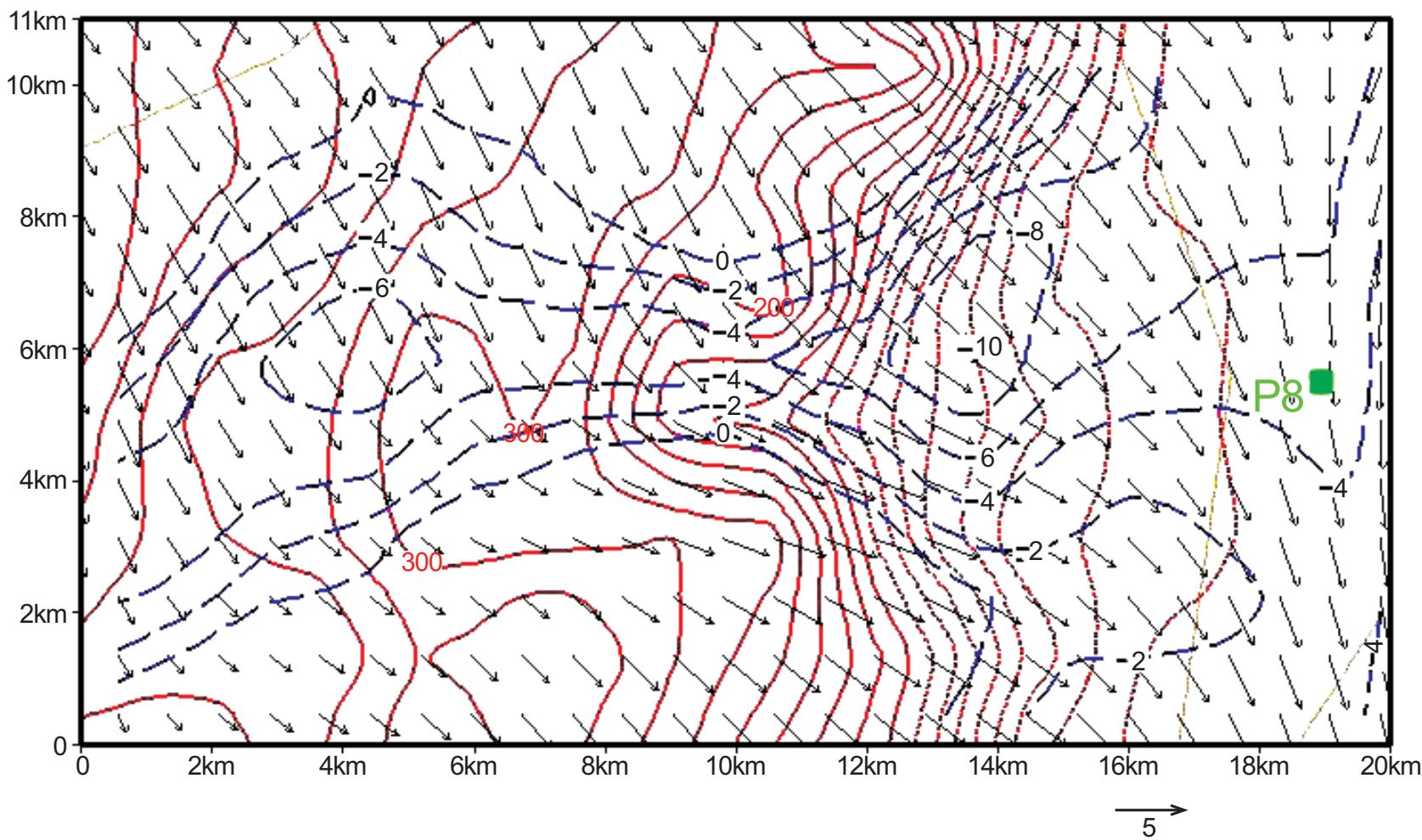

Fig. (7a). Surface wind flow pattern (black arrows, unit is $\mathrm{m} / \mathrm{s}$ ), contour of topography (red, dot red line indicates the negative height of topography with interval 50 meters) and contour of wind divergence (blue, dashed, unit is $\cdot 10^{-4} \mathrm{~s}^{-1}$, contour interval $2 \cdot 10^{-4} \mathrm{~s}^{-1}$ ) for the Zeelim Wadi at 3:00 UTC $6^{\text {th }}$ Sep 2005.

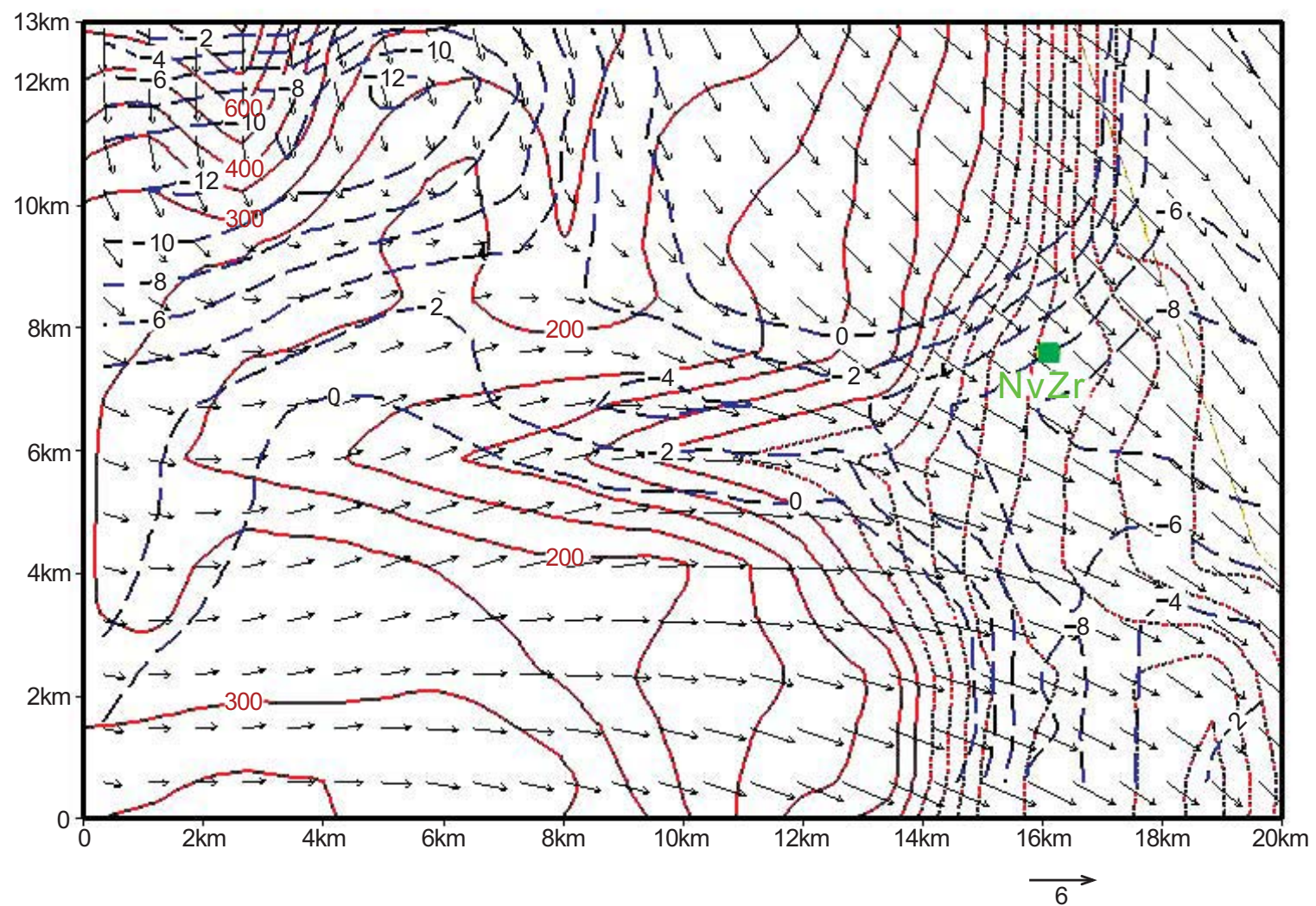

Fig. (7b). Same as Fig. (4a), but for the Chemar Wadi. 
Table 1A. Vertical Profile of the Wind Speed (kt) and Direction from the Ground to 1000m Elevation. The Profile was Measured by a Radiosonde on 5 Sept., 2005 at 21:00 LT at Nve-Zohar

\begin{tabular}{|c|c|c|c|c|}
\hline No. & Altitude (m) & Velocity (kt) & Direction (deg) & Wind Vector \\
\hline 1 & Ground-wind & 4.0 & 330 & $\Delta$ \\
\hline 2 & $0-150$ & 10.5 & 330 & 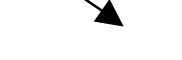 \\
\hline 3 & $150-300$ & 8.1 & 346 & 4 \\
\hline 4 & $300-450$ & 15.6 & 008 & \\
\hline 5 & $450-600$ & 15.5 & 012 & \\
\hline 6 & $600-750$ & 14.8 & 024 & \\
\hline 7 & $750-900$ & 13.7 & 018 & \\
\hline 8 & $900-1060$ & 14.8 & 019 & \\
\hline
\end{tabular}

resulting in NW direction of the ground wind at Nve-Zohar at night.

\section{b. Ground Observations}

Table 2 compares the winds at night in the two close ground stations of P8 and P5. As mentioned earlier P8 is located next to Zeelim Wadi, in contrast to P5 that has no wadi next to it. This enables us to use P5 as reference to the wind in P8 when ignoring other presumably secondary factors, like the vicinity to the Dead Sea etc. The range of the wind direction at night in P8 is $313-346^{\circ}$, while at P5 it is a broader range of $306-027^{\circ}$. This can be associated with channeling of the wind at P8 by the Zeelim Wadi. The Wadi also seems to intensify the wind by its channeling. The average wind speed at P8 is $7.7 \mathrm{~m} / \mathrm{sec}$, while at P5 the average at the same time is only $5.6 \mathrm{~m} / \mathrm{sec}$. Like in the vertical profiles verification there is also here a rotation of the wind from the wadi axis to the upper-level wind, resulting in wind channeling by the wadi of North-Westerly near ground at night, and some contribution of different land/sea factor.

\section{SUMMARY AND CONCLUSIONS}

The evidence presented here illustrated the wind channeling by very small wadis at the Dead-Sea. Previous works have not shown channeling in such small rivers. The reason for this is that not only the meteorological mesoscale models 
Table 1B. Same as Table 1A but for 7 Sept., 2005 06:00 LT

\begin{tabular}{|c|c|c|c|c|}
\hline No. & Altitude (m) & Velocity (kt) & Direction (deg) & Wind Vector \\
\hline 1 & Ground-wind & 3.0 & 230 & \\
\hline 2 & $0-100$ & 5.2 & 316 & \\
\hline 3 & $100-200$ & 5.8 & 360 & \\
\hline 4 & $200-300$ & 6.1 & 001 & \\
\hline 5 & $300-400$ & 6.7 & 005 & \\
\hline 6 & $400-500$ & 6.9 & 012 & \\
\hline 7 & $500-600$ & 6.8 & 013 & \\
\hline 8 & $600-700$ & 6.4 & 007 & \\
\hline 9 & $700-800$ & 7.5 & 011 & \\
\hline 10 & $800-1000$ & 9.0 & 017 & \\
\hline
\end{tabular}

on the meso- $\gamma$ scale $(2-20 \mathrm{~km}$ resolution) are still relatively difficult to operate, but also primarily due to the lack of suitable observations in such small areas. The wind channeling seems to exist in three wadis at the Dead Sea, and was verified by meso- $\gamma$ meteorological model simulations as well as by surface and upper layers observations.
The main mechanisms for the channeling seem to be thermally driven with the forced channeling mechanisms. The pictures of the model output at 3:00 a.m. UTC on $6^{\text {th }}$ Sep 2005 show a good thermal driving mechanism. This in spite of the problem in simulating small-scale flow under strongly stratified conditions. In this time synoptic wind effects are 
Table 2. Time Series of the Wind Speed $(\mathrm{m} / \mathrm{sec})$ and Direction Measured at the Ground Stations of P8 and P5, from 5 Sept., 2005 , 19:00 Till 6 Sept., 04:00 Every Half Hour. At the Bottom the Averages are Displayed Along with the Range of the Directions

\begin{tabular}{|c|c|c|c|c|c|c|c|}
\hline Date & Time & P8 Velocity $(\mathrm{m} / \mathrm{sec})$ & P8 Direction (deg) & P8 Wind Vector & P5 Velocity $(\mathrm{m} / \mathrm{sec})$ & P5 Direction (deg) & P5 Wind Vector \\
\hline $5 / 9 / 05$ & 19:00 & 6.0 & 337 & & 6.3 & 007 & \\
\hline $5 / 9 / 05$ & $19: 30$ & 8.3 & 323 & & 6.2 & 005 & \\
\hline $5 / 9 / 05$ & 20:00 & 12.4 & 324 & & 8.4 & 306 & \\
\hline $5 / 9 / 05$ & $20: 30$ & 10.1 & 327 & & 9 & 309 & $\Delta$ \\
\hline $5 / 9 / 05$ & 21:00 & 9.8 & 327 & & 9.2 & 308 & $\Delta$ \\
\hline $5 / 9 / 05$ & 21:30 & 8.7 & 333 & & 7.5 & 321 & $\mathbf{\Delta}$ \\
\hline $5 / 9 / 05$ & 22:00 & 9.4 & 333 & & 7.2 & 355 & \\
\hline $5 / 9 / 05$ & $22: 30$ & 9.5 & 337 & & 8.0 & 342 & \\
\hline $5 / 9 / 05$ & 23:00 & 9.6 & 346 & & 6.2 & 355 & \\
\hline $5 / 9 / 05$ & 23:30 & 9.3 & 336 & & 6.6 & 008 & \\
\hline $6 / 9 / 05$ & 00:00 & 9.2 & 345 & & 5.1 & 357 & \\
\hline $6 / 9 / 05$ & 00:30 & 7.1 & 340 & & 4.2 & 005 & \\
\hline 6/9/05 & 01:00 & 5.7 & 345 & & 2.9 & 337 & \\
\hline 6/9/05 & 01:30 & 4.9 & 327 & 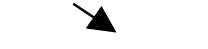 & 3.6 & 347 & \\
\hline 6/9/05 & 02:00 & 5.3 & 319 & & 2.4 & 027 & 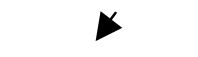 \\
\hline $6 / 9 / 05$ & 02:30 & 5.6 & 335 & & 2.1 & 002 & $\nabla$ \\
\hline $6 / 9 / 05$ & 03:00 & 4.1 & 318 & $\Delta$ & 3.1 & 324 & $\Delta$ \\
\hline $6 / 9 / 05$ & 03:30 & 5.2 & 326 & & 3.8 & 315 & $\Delta$ \\
\hline \multirow[t]{2}{*}{$6 / 9 / 05$} & 04:00 & 5.8 & 313 & $\Delta$ & 4.9 & 313 & \\
\hline & & $\begin{array}{c}\text { Average } \\
7.68\end{array}$ & $\begin{array}{c}\text { Range } \\
313-346\end{array}$ & & $\begin{array}{c}\text { Average } \\
5.62\end{array}$ & $\begin{array}{c}\text { Range } \\
306-027\end{array}$ & \\
\hline
\end{tabular}


reduced near the surface and the local wind circulation becomes dominant. Also, the very dense content of salt in the dead-sea water and the large area of sea-surface made the thermal driving mechanism to be a dominant factor (high heat capacity of Dead-Sea water). The lack of vegetation cover in our study area and the big diurnal temperature changes further enhance this channeling mechanism. Forced channeling mechanism is also a dominant factor. It can be seen from both above charts that the wind flows are horizontally along the wadis. The wind divergence field picture as well as the tilting of the upper-level wind, shown by the observations, also approves our finding.

It maybe concluded that high resolution meso scale model is an attractive tool to study some micro climate studies, not only at the meso- $\beta$ as suggested by many studies but also at the meso- $\gamma$ synoptic scale which has shown a credible performance in this research. Also, the unique features of the Dead-Sea i.e., the absence of vegetation cover and urban areas can serve as a proposed natural model for the wind-wadi interaction.

\section{ACKNOWLEDGEMENTS}

We wish to thank the Dead-Sea Works that supported the research by their grant. We thank Alex Kalmikov for his help in running the MM5 model. The research was also partly supported by the GLOWA - Jordan River Project funded by the German Ministry of Science and Education (BMBF), in collaboration with the Israeli Ministry of Science and Technology (MOST). We are thankful to Moti Aharoni, Ofir Cohen and the entire Dead-Sea team, and Oded Potchter and Yaron Yaakov from the Geography Dept. of the Tel Aviv University for their support. The Dead-Sea satellite picture of Fig. (1) was taken from the United Nations Environmental Program (UNEP) DEWA/GRID-Europe website.

\section{REFERENCES}

[1] Wagner A. Der ta"gliche Luftdruck- und Temperaturgang in der freien Atmospha"re und in Gebirgsta"lern. Gerlands Beitr Geophys 1932; 37: $315-44$.
[2] Ekhart E. Neuere Untersuchungen zur Aerologie der Talwinde: Die periodischen Tageswinde in einem Quertale der Alpen. Beitr Phys Atmos 1934; 21: 245-68.

[3] Whiteman CD, Doran JC. The relationship between overlying synoptic-scale flows and winds within a Valley. Appl Meteor 1993; 32: $1669-82$

[4] Whiteman CD. Observations of thermally developed wind systems in mountainous terrain. Atmospheric Processes over Complex Terrain. Meteor Monogr Amer Meteor Soc 1990; 45: 5-42.

[5] Egger J. Thermally forced flows: Theory. Atmospheric Processes over Complex Terrain, Meteor Monogr Amer Meteor Soc 1990; 45: 43-58.

[6] Mahrt L, Vickers D, Nakamura R, et al. Shallow drainage flows. Bound Lay Meteor 2001; 101: 243-260.

[7] Gross G, Wippermann F. Channeling and countercurrent in the upper Rhine valley: numeric simulations. J Clim Appl Meteor 1987; 26: 1239-1304.

[8] Eckman RM. Observations and numerical simulations of winds within a broad forested valley. J Appl Meteor 1998; 37: 206-19.

[9] De Wekker SFJ, Steyn DG, Fast JD, Rotach MW, Zhong S. The performance of RAMS in representing the convective boundary layer structure in a very steep valley. Environ Fluid Mech 2005; 5 : 35-62.

[10] Webber RO, Kaufmann P. Relationship of synoptic winds and complex terrain flows during MISTRAL field experiments. J Appl Meteor 1998; 37: 1468-96.

[11] Cogliati MG, Mazzeo NA. Air flow analysis in the upper Rio Negro Valley (Argentina). Atmos Res 2006; 80: 263-79.

[12] Bajic A. Small valley wind characteristics - an observational study. Z Meteor 1990; 40: 377-82.

[13] Mursch-Radlgruber E. Observations of flow structure in a small forested valley system. Theor Appl Climatol 1995; 52: 3-17.

[14] Seaman NL, Gaudet B, Deng A, et al. Evaluation of meander-like wind variance in high-resolution WRF model simulations of the stable noctural boundary layer. Proceeding of the 15 th joint conference on the applications of air pollution meteorology with the A\&WMA 10th conference on atmospheric chemistry, 2008.

[15] Alpert P, Shafir H, Issahary D. Recent changes in the climate of the Dead Sea Valley. Climatic Change 1997; 7: 1-25.

[16] Alpert P, Eppel A. A proposed index for mesoscale activity. J Clim Appl Meteor 1985; 24: 472-80.

[17] Alpert P, Cohen A, Neumann J, Doron E. A model simulation of the summer circulation from the Eastern Mediterranean past Lake Kinneret in the Jordan Valley. Mon Wea Rev 1982; 110: 994-1006.

[18] Grell GA, Dudhia J, Stauffer DR. A description of the fifthgeneration Penn State/NCAR mesoscale model (MM5). NCAR Technical Note, NCAR/TN-398+STR, 117 pp. 1994. 